\title{
NMDA receptor subunits are modified transcriptionally and post-translationally in the brain of streptozotocin-diabetic rats
}

\author{
M. Di Luca ${ }^{1}$ L. Ruts ${ }^{2}$, F. Gardoni ${ }^{1}$, F. Cattabeni ${ }^{1}$, G.J. Biessels ${ }^{2}$, W.H. Gispen ${ }^{2}$ \\ ${ }^{1}$ Institute of Pharmacological Sciences, University of Milan, Milan, Italy \\ ${ }^{2}$ Department of Medical Pharmacology, Rudolf Magnus Institute for Neurosciences, University of Utrecht, Utrecht, \\ The Netherlands
}

\section{Abstract}

Aims/hypothesis. Moderate disturbances of learning and memory were recognized as a complication of diabetes mellitus in patients. The streptozotocin-diabetic rat, an animal model of insulin-dependent diabetes, shows impairments in spatial memory and in long-term potentiation expression. We have studied the effect of experimental diabetes on expression of post-synaptic glutamate N-Methyl-D-Aspartate ionotropic receptors and of other key proteins regulating synaptic transmission at the post-synaptic compartment.

Methods. In situ hybridization and Western blot analysis were used to assess expression and protein concentration of N-Methyl-D-Aspartate receptors and $\alpha$-calcium-calmodulin-dependent kinase II. Receptor subunits $\alpha$ CaMKII-dependent phosphorylation was studied in post-synaptic densities obtained from the hippocampus and cortex of control, streptozotocindiabetic and insulin-treated rats.

Results. The transcript levels of NR1 and NR2A subunits of N-Methyl-D-Aspartate were unchanged in rats with a diabetic duration of 3 months when compared with age-matched control rats. Accordingly, NR1 and NR2A as well as GluR1, GluR2/3, PSD-95 and $\alpha$ CaMKII protein concentrations in post-synaptic densities were the same in both control and diabetic rats, whereas the immunoreactivity for NR2B was reduced by about $40 \%$. In addition, the activity of $\alpha \mathrm{CaMKII}$ on exogenous substrates, such as syntide-2, and the phosphorylation of NR2A/B subunits of N-Methyl-D-Aspartate receptor was reduced in hippocampal post-synaptic densities of streptozotocin-diabetic rats as compared with control rats. Furthermore, we show that insulin intervention for 3 months after diabetic duration partially restored both $\alpha$ CaMKII activity and NR2B levels.

Conclusion/interpretation. N-Methyl-D-Aspartate receptor expression and phosphorylation is possibly involved in behavioural and electrophysiological abnormalities observed in streptozotocin-diabetic rats. [Diabetologia (1999) 42: 693-701]

Keywords Synaptic plasticity, hippocampus, rat, CaMKII, NMDA receptor, long-term potentiation.
Received: 6 October 1998 and in revised form: 22 December 1998

Corresponding author: M. Di Luca, PhD, University of MilanInstitute of Pharmacological Sciences, via Balzaretti 9, 20133Milan, Italy

Abbreviations: PSD, Post synaptic densities; LTP, long-term potentiation; LTD, long-term depression; NMDA, N-MethylD-Aspartate; AMPA, 1- $\alpha$-amino-3-hydroxy-5-methyl-4-isoxazole propionic acid; CaMKII, calcium-calmodulin dependent protein kinase II; PMSF, phenyl-methyl sulphonyl fluoride; STZ, streptozotocin; CNS, central nervous system; NGF, nerve growth factor.
Diabetes mellitus is known to be associated with neurological complications in both the peripheral and the central nervous system. Manifestations of cerebral disorders in diabetic patients include alterations in neurotransmission, electrophysiological abnormalities, structural changes and cognitive deficits [1-4]. In animal models of diabetic pathology, such as the streptozotocin-diabetic rat, spatial learning impairments have been reported [5]. This cognitive deficit is associated with changes in hippocampal synaptic plasticity, including an impaired expression of long term potentiation (LTP) $[5,6]$ and enhanced expres- 
Table 1. Final body weight and blood glucose in untreated STZ-diabetes (upper half) and in the insulin reversal experiment (lower half)

\begin{tabular}{llccc}
\hline & $\begin{array}{l}\text { Body weight } \\
4 \text { months }(\mathrm{g})\end{array}$ & $\begin{array}{l}\text { Blood glucose } \\
4 \text { months }(\mathrm{mmol} / \mathrm{l})\end{array}$ & $\begin{array}{l}\text { Body weight } \\
7 \text { months }(\mathrm{g})\end{array}$ & $\begin{array}{l}\text { Blood glucose } \\
7 \text { months }(\mathrm{mmol} / \mathrm{l})\end{array}$ \\
\hline Untreated & & & & \\
Control $(n=20)$ & $573 \pm 16$ & $5.2 \pm 0.2$ & & \\
Diabetic $(n=28)$ & $309 \pm 13$ & $20.7 \pm 1.0^{\mathrm{a}}$ & & $629 \pm 19$ \\
Insulin reversal treatment & & $5.5 \pm 0.4$ & $5.7 \pm 0.4$ \\
Control $(n=7)$ & $599 \pm 18$ & $20.5 \pm 1.9^{\mathrm{a}}$ & $272 \pm 11^{\mathrm{a}}$ & $20.8 \pm 1.3$ \\
Diabetic $(n=7)$ & $289 \pm 10^{\mathrm{a}}$ & $22.6 \pm 1.2^{\mathrm{a}}$ & $482 \pm 11^{\mathrm{a}, \mathrm{b}}$ & $6.7 \pm 1.2^{\mathrm{b}}$ \\
Insulin $(n=6)$ & $310 \pm 25^{\mathrm{a}}$ & & \\
\hline
\end{tabular}

In the insulin reversal experiment, treatment was initiated 4 months after induction of diabetes and continued for 3 months. Data are mean \pm SEM and were analysed by one

sion of long-term depression (LTD) [7]. LTP and LTD are activity-dependent modifications of synaptic strength, which have attracted considerable attention in the search for the cellular mechanisms of learning and memory. LTP can be defined as a prolongued enhancement of the efficacy of excitatory synaptic transmission, whereas LTD can be defined as a prolongued reduction of the efficacy of excitatory synaptic transmission. Both LTP and LTD can be elicited in the brain in vivo and in vitro by stimulation of excitatory afferents $[8,9]$. The molecular mechanisms underlying these changes in hippocampal plasticity are largely unknown. It is tempting to suggest, however, that factors that would affect the frequency-dependent rise in postsynaptic calcium concentration, such as alterations in ionotropic glutamate receptors or in the activity of phosphatases and kinases or both, are involved. It is generally accepted that LTP and LTD induction involves a differential rise in $\mathrm{Ca}^{2+}$ concentration in the postsynaptic cell. The different calcium concentrations achieved by the different stimulation paradigms necessary to induce LTP and LTD are thought to change the degree of protein phosphorylation, through activation of either kinases (LTP) or phosphatases (LTD) or both [10-12].

It is known that excitatory transmission in the brain is largely mediated by glutamate acting through different classes of receptors: ionotropic [1- $\alpha$-amino-3-hydroxy-5-methyl-4-isoxazole propionic acid (AMPA) and N-Methyl-D-Aspartate (NMDA)] and metabotropic (mGluRs). In excitatory synapses the frequency-dependent $\mathrm{Ca}^{2+}$ influx is mediated largely by NMDA receptors. NMDA receptors are heteromeric glutamate-gated ion channels in the central nervous system (CNS) $[13,14]$ and are formed by monomers of two families of homologous subunits NR1 and NR2A-D that are differentially expressed in the CNS [15]. These receptors are highly enriched in post-synaptic densities (PSD) [16,17]. PSD is a fibrous specialization of cytoskeletal elements adhering to the postsynaptic membrane and serving as scaffold for neurotransmitter receptors and accessory proteins. In iso- way analysis of variance with Duncan's multiple range test; ${ }^{\mathrm{a}} p<0.01$ (diabetic vs control); ${ }^{\mathrm{b}} p<0.01$ (insulin treated vs untreated diabetic)

lated PSD, AMPA and NMDA receptors are highly enriched $[16,18,19]$ and so are different classes of kinases such as the non-receptor tyrosine kinase src and the multifunctional $\mathrm{Ca}^{2+} / \mathrm{CaM}$ dependent protein $\mathrm{ki}$ nase II (CaMKII), the latter comprising up to $30 \%$ of the total PSD proteins [16, 19]. Specific substrates for CaMKII in PSD are AMPA receptors, whose phosphorylation is increased during LTP [20], and NMDA receptor subunits $[21,25]$.

Therefore, we studied the effects of experimental diabetes on the postsynaptic molecular machinery involved in hippocampal synaptic plasticity. We focused on the postsynaptic compartment since paired pulse facilitation, an electrophysiological tool for detecting changes in presynaptic processes involved in neurotransmitter release [22], was unaffected in diabetic rats [5]. In particular, we have addressed the questions whether the disturbances in hippocampal synaptic plasticity in diabetic rats are associated with i) a changed composition of NMDA receptors, thus implying changed expression of specific subunits and ii) changes in and phosphorylation of specific subunits of NMDA receptor, as the result of changes in CaMKII activity.

\section{Materials and methods}

Experimental design. Male Wistar rats (starting weight $\pm 300 \mathrm{~g}$, UWU-CPD, Harlan, Utrecht, The Netherlands) were used. Diabetes mellitus was induced by a single intravenous injection of streptozotocin (STZ) (Serve Feinbiochemia GMBH, Heidelberg, Germany) at a dose of $40 \mathrm{mg} / \mathrm{kg}$ body weight dissolved in saline.

The experimental groups consisted of: 1) rats with a diabetic duration of 4 months $(n=20)$; 2) age-matched nondiabetic control rats $(n=28)$; 3) rats with a diabetic duration of 7 months $(n=7)$; 4$)$ rats with a diabetic duration of 4 months followed by 3 months of insulin intervention treatment $(n=6) ; 5)$ age-matched control rats $(n=7)$.

Insulin was given through subcutaneous sustained release insulin implants at a dose of 2-4 IU per day (Linplant, Mollegaard, Ejby, Denmark). Glucose concentrations were measured every 2 weeks in the insulin-treated animals in blood 
samples, obtained by tail prick, by a strip-operated blood glucose sensor (Companion2, Medisense Ltd, Birmingham, UK), (Table 1).

Antibodies and probes. Antibodies against $\alpha$ CaMKII were purchased from Boehringer (Mannheim, Germany) and antibodies against NR1, NR2A, NR2B, and GluR2/3 from Chemicon (Tamecula Calif., USA). PSD95 was from Affinity Bioreagents (Golden, USA).

The probes for NR1, NR2A were synthesized by Primm Laboratories (Milan, Italy) and the probe for NR2B by MWG Biotech (Ebersberg, Germany) according to the sequence reported previously [15].

Post-synaptic density preparation. To isolate PSD from rat cortex and hippocampus, a modification of the method by Carlin et al. [23] was used. Briefly, animals were killed by decapitation and cerebral cortex (6 rats/preparation) and hippocampus (6-10 animals/preparation) were rapidly dissected and pooled. Since it has been suggested that CaMKII could translocate to the PSD post-mortem [24], not more than 2 min elapsed between decapitation and tissue processing; if more, the tissue specimen were discarded. Homogenization was carried out by 10 strokes in a Teflon-Glass homogenizer $(700 \mathrm{rev} / \mathrm{min})$ in $4 \mathrm{ml} / \mathrm{g}$ of cold sucrose $0.32 \mathrm{~mol} / \mathrm{l}$ containing HEPES $1 \mathrm{mmol} / \mathrm{l}$, $\mathrm{MgCl}_{2} 1 \mathrm{mmol} / 1, \mathrm{NaHCO}_{3} 1 \mathrm{mmol} / \mathrm{l}, \mathrm{pH} 7.4$ in presence of a complete set of proteases inhibitors (Complete, Boehringer Mannheim Gmbh, Mannheim, Germany). The homogenized tissue was centrifuged at $1000 \times g$ for $10 \mathrm{~min}$. The resulting supernatant was centrifuged at $3000 \times g$ for 15 min to obtain a fraction of mitochondria and synaptosomes. The pellet was resuspended in a $2.4 \mathrm{ml} / \mathrm{g}$ of $0.32 \mathrm{~mol} / \mathrm{l}$ sucrose, overlaid on sucrose gradient $(0.85-1.0-1.2 \mathrm{~mol} / \mathrm{l})$ and centrifuged at $82500 \times g$ for $2 \mathrm{~h}$. The fraction between 1.0 and $1.2 \mathrm{~mol} / \mathrm{l} \mathrm{su}-$ crose was removed and diluted with an equal volume of $1 \%$ Triton X-100 in sucrose $0.32 \mathrm{~mol} / \mathrm{l}$ in HEPES $1 \mathrm{mmol} / \mathrm{l}$ and stirred at $4{ }^{\circ} \mathrm{C}$ for $15 \mathrm{~min}$. This solution was spun down at $82500 \times \mathrm{g}$ for $30 \mathrm{~min}$. The pellet was resuspended, layered on sucrose gradients (1.0-1.5-2.1 mol/1) and centrifuged at $100000 \times g$ at $4{ }^{\circ} \mathrm{C}$ for $2 \mathrm{~h}$. The fraction between 1.5 and $2.1 \mathrm{~mol} / \mathrm{l}$ was removed and diluted with an equal volume of $1 \%$ Triton X-100 and $\mathrm{KCl}$ $150 \mathrm{mmol} / \mathrm{l}$. PSD were finally collected by centrifugation at $100000 \times g$ at $4^{\circ} \mathrm{C}$ for $30 \mathrm{~min}$ and stored at $-80^{\circ} \mathrm{C}$.

Endogenous phosphorylation and immunoprecipitation. CaMKII-dependent endogenous phosphorylation of PSD proteins and immunoprecipitation assays were done as described previously [25]. Briefly, one $\mu \mathrm{g}$ of purified PSD either from cortex or from hippocampus was incubated in a buffer solution containing: HEPES $20 \mathrm{mmol} / \mathrm{l}, \mathrm{pH} 7.4, \mathrm{MgCl}_{2} 10 \mathrm{mmol} / \mathrm{l}$, Okadaic acid $10^{-5} \mathrm{~mol} / \mathrm{l}$ (Sigma, St. Louis, Mo., USA), phenyl-methylsulphonyl fluoride (PMSF) $100 \mu \mathrm{mol} / \mathrm{l}$, DTT $20 \mathrm{mmol} / \mathrm{l}$ with $100 \mu \mathrm{mol} / 1$ of $\gamma_{-}{ }^{32} \mathrm{P}$-ATP $(1 \mu \mathrm{Ci} / \mathrm{tube} ; 5000 \mathrm{Ci} / \mathrm{mmol}$; Amersham International plc, Little Chalfont, UK) in the presence of either $1 \mathrm{mmol} / \mathrm{l} \mathrm{CaCl}_{2}$ and $40 \mu \mathrm{g} / \mathrm{ml}$ calmodulin or of $1 \mathrm{mmol} / \mathrm{l}$ EGTA. Reactions were carried out at $37^{\circ} \mathrm{C}$ for $5 \mathrm{~min}$ and were stopped either by the addition of the electrophoresis sample buffer (SDS 2\%, glycerol $10 \%, \beta$-mercaptoethanol $5 \%, 62.5 \mathrm{mmol} / \mathrm{l}$ Tris- $\mathrm{HCl} \mathrm{pH} 6.8$ ) or by immersing in liquid nitrogen. Proteins were separated by SDS-PAGE (Running gel: acr. $6 \%$ ) and phosphoproteins shown by autoradiography. Quantification was done by computerized assisted image analysis (software: NIH-Image, Bethesda, Md., USA).

For immunoprecipitation, post-synaptic density proteins were incubated in buffer B containing: $\mathrm{NaCl} 200 \mathrm{mmol} / \mathrm{l}$, EDTA $10 \mathrm{mmol} / \mathrm{l}, \mathrm{Na}_{2} \mathrm{HPO}_{4} 10 \mathrm{mmol} / \mathrm{l}, \mathrm{NP}-400.5 \%$, SDS $0.1 \%$ in a final volume of $400 \mu \mathrm{l}$ with antibodies against NR2A/ $\mathrm{B}$ or CaMKII as indicated in the text (dilution 1:100) overnight at $4{ }^{\circ} \mathrm{C}$. Protein A-agarose beads ( $5 \mathrm{mg} /$ tube) or staphylococcus aureus cowan I cells $(0.5 \%)$ washed in the same buffer, were added and incubation was continued for $2 \mathrm{~h}$. The beads were collected by centrifugation and washed three times with buffer $A$. Sample buffer for SDS-PAGE was added and the mixture was boiled for $3 \mathrm{~min}$. Beads were pelletted by centrifugation and a volume of supernatants was applied to SDS-PAGE $6 \%$.

CaMKII assay. CaMKII activity was measured according to Fukunaga et al. [26]. Briefly, one $\mu \mathrm{g}$ of PSD proteins prepared from cortex and hippocampus were incubated in a medium containing: HEPES $50 \mathrm{mmol} / \mathrm{l}, \mathrm{pH} 7.4, \mathrm{Mg}$ acetate $10 \mathrm{mmol} / \mathrm{l}$, $100 \mu \mathrm{mol} / 1 \gamma^{3}{ }^{32} \mathrm{P}$-ATP, syntide- $240 \mu \mathrm{mol} / \mathrm{l}, \mathrm{CaCl}_{2} 1 \mathrm{mmol} / \mathrm{l}$ and calmodulin $40 \mu \mathrm{g} / \mathrm{ml}$ in a final volume of $25 \mu \mathrm{l}$. Reactions were carried out at $37^{\circ} \mathrm{C}$ for $5 \mathrm{~min}$ and stopped by spotting on phosphocellulose paper.

In situ hybridization. In situ hybridization of NR1, NR2A and NR2B mRNA was carried out as described in another report [27]. Adult male Wistar rats were killed and and their brain removed rapidly and stored at $-80^{\circ} \mathrm{C}$, until processed. $12 \mu \mathrm{m}$ thick sections from control animals and diabetic rats were thawmounted onto gelatin-coated microscope slides and subsequently fixed in $4 \%$ paraformaldehyde in phosphate buffered saline (PBS). Prehybridization and hybridization reactions were done as described previously $[28,29]$ with oligonucleotide probes radiolabelled at the 3 '-end with $\alpha-\left[{ }^{35} \mathrm{~S}\right] \mathrm{dATP}$ (DupontNEN, Boston, Mass., USA; $1400 \mathrm{Ci} / \mathrm{mmol}$ ) using terminal deoxynucleotidyl transferase. Quantification was done by computerized assisted image analysis (software: NIH-Image).

\section{Results}

$N R 1, N R 2 A, N R 2 B$ gene expression. In situ hybridization histochemistry was used to investigate the expression of NMDA receptor subunits in the brains of diabetic rats.

Figure 1 shows a representative autoradiogramme of NR1, NR2A, NR2B subunit expression in control (C) and diabetic rats (D). In control rats transcripts of NR1, NR2A and NR2B subunits show the same anatomical localization, as reported previously [15] for adult brain. Quantitative analysis done on coronal slices from three different animals per group, at two different levels [30], showed that in control brains, the level of transcripts for NR2B was much lower than for NR2A, as expected in adult rats. The diabetic condition did not change either the anatomical localization or the level of NR1 and NR2 A subunits transcript. The mRNA levels of NR2B in diabetic rats are, however, reduced when compared with control rats. Indeed, semiquantitative analysis of transcripts showed a decrease of $37.4 \pm 5.8 \%$ in the NR2B mRNA levels in the hippocampus of diabetic rats when compared with control rats $(p<0.01$ vs diabetic brains vs control brains).

NR1, NR2A and $2 B$ protein level and phosphorylation in post-synaptic densities of control and diabetic rats. To evaluate protein concentrations of glutamate receptors and signalling proteins, such as CaMKII, 


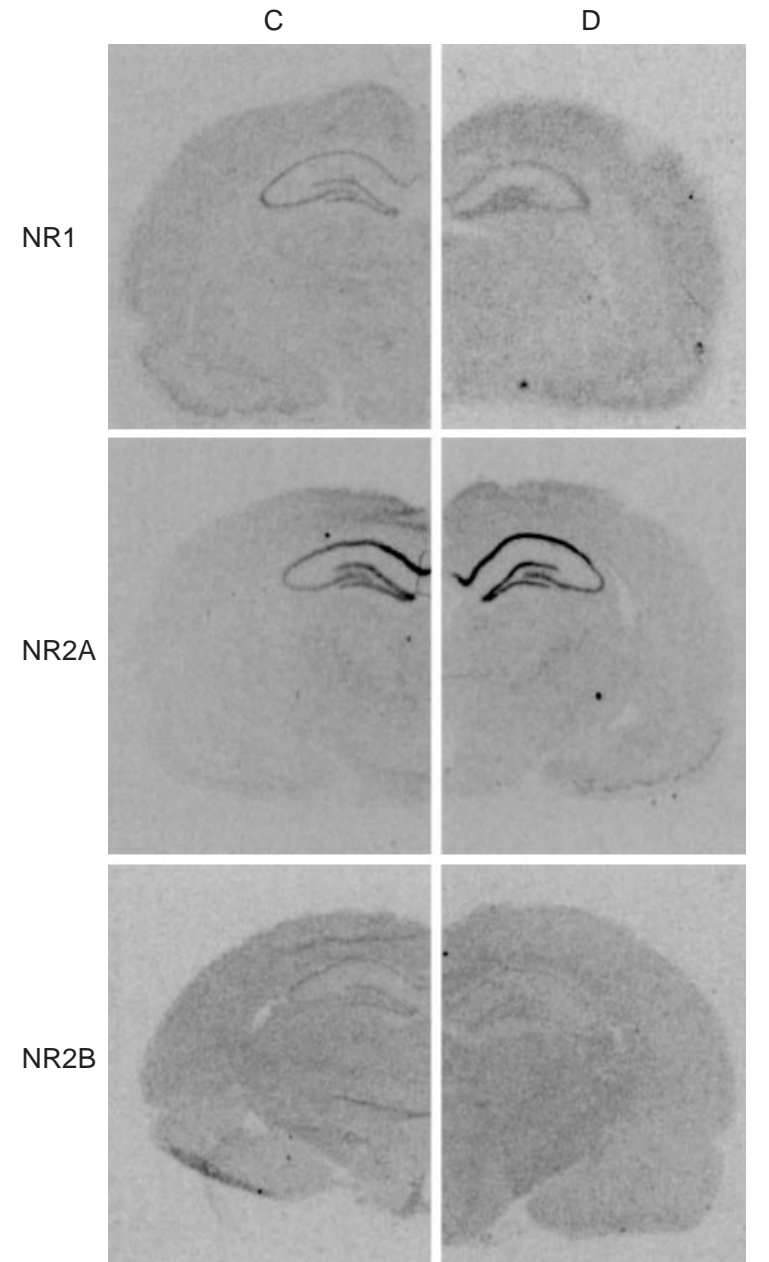

Fig. 1. Hybridization signal of radiollabeled NR1, NR2A and NR2B $(n=4)$ in control (C) and diabetic rats (D). No differences are observed in the expression of transcripts for NR1 and NR2A. NR2B mRNA levels are reduced by $37.4 \pm 5.8 \%$, as shown by densitometric analysis (NIH Image, $p<0.01$ vs control; means of six acquisitions at two different levels)

Western blot analyses were done on PSD obtained from the cortex and hippocampus of control and diabetic rats. Figure 2 shows that the immunostaining of NR1 and NR2A is the same in hippocampal PSD of both control and diabetic rats. In contrast, the Western blot analysis for NR2B showed a reduction of about $40 \%$ in hippocampal PSD of diabetic rats compared with control rats, in agreement with in situ hybridization studies. In addition, the concentration of proteins highly enriched in PSD such as $\alpha \mathrm{CaMKII}$ and PSD-95, a marker for PSD [19], is the same in control and diabetic rats, thus suggesting that the composition of postsynaptic densities is the same in control and diabetic rats. Similar results were obtained in cerebral cortex PSD (data not shown).

We then tested the possible effect of diabetes on the phosphorylation of the NMDA receptor subunits. It has been shown that in adult brain PSD, the NMDA receptor subunits are substrates for CaMKII

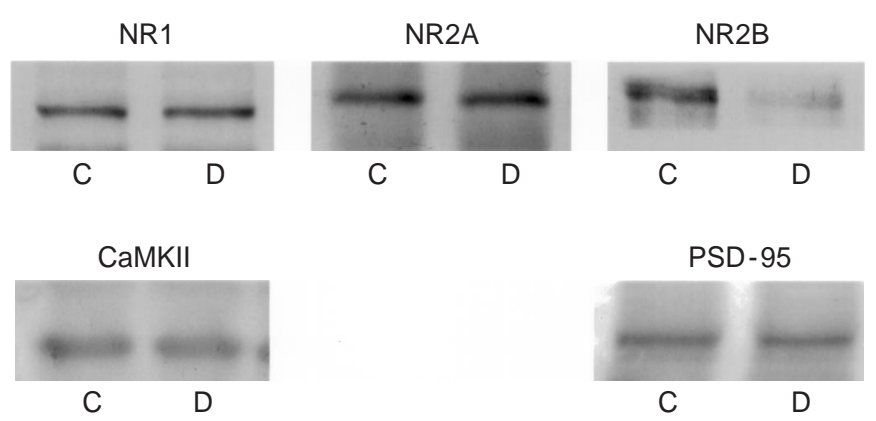

Fig. 2. Representative Western blot of, NR1, NR2A, NR2B, $\alpha$ CaMKII and PSD-95 in hippocampal PSD from control (C) and diabetic (D) rats. Experiments were done on three independent PSD preparations (10 animals/ group)

$[21,25]$. PSD purified from cortex and hippocampus of both control and diabetic rats reacted under conditions known to obtain $\mathrm{Ca}^{2+} / \mathrm{CaM}$ dependent phosphorylation and proteins were resolved in SDSPAGE. Figure 3 shows a representative autoradiogramme of endogenous CaMKII-dependent phosphorylation of PSD proteins obtained from hippocampus of control and diabetic rats. There was no detectable difference in basal phosphorylation of PSD proteins between control and diabetic rats. The addition of $\mathrm{Ca}^{2+} / \mathrm{CaM}$ stimulated ${ }^{32} \mathrm{P}$-phosphate incorporation into many protein bands in both experimental groups, when compared with magnesium-dependent basal (calcium-independent) phosphorylation (Fig. 3), albeit to a lesser degree in the diabetic condition. Similar results were obtained using PSD purifed from cerebral cortex.

When phosphorylated PSD proteins were quantitatively immunoprecipitated using anti-NR2A/B polyclonal antibody, a phosphorylated band at 170 $\mathrm{kDa}$ is evident, corresponding to receptor subunits NR2A/B (Fig. 4; immunoprecipitation from hippocampal PSD). In diabetic rats the $\mathrm{Ca}^{2+} / \mathrm{CaM}$ stimulated phosphorylation of the immunoprecipitated $\mathrm{NR} 2 \mathrm{~A} / \mathrm{B}$ is decreased when compared with control rats in agreement with results shown in Fig. 3. In the same autoradiogramme a phosphorylated band at 50 $\mathrm{kDa}$ is also present, consistent with previous findings showing that autophosphorylated $\alpha$-subunit of CaMKII co-precipitates with NR2A/B [25]. In addition, when phosphorylated PSD from the hippocampus of control and diabetic rats are immunoprecipitated with polyclonal antibodies recognizing specifically NR2A and NR2B, a decrease in the phosphorylation of both NMDA receptor subunits was observed (data not shown).

The observed net decrease in the ${ }^{32} \mathrm{P}$-incorporation in NR2A/B subunits in diabetic rats can be due not only to the decrease in the substrate concentration (NR2B), but also either to a decrease in the activity of the kinase or to an increased in vivo phosphorylation preceding the post-hoc assay. To clarify 


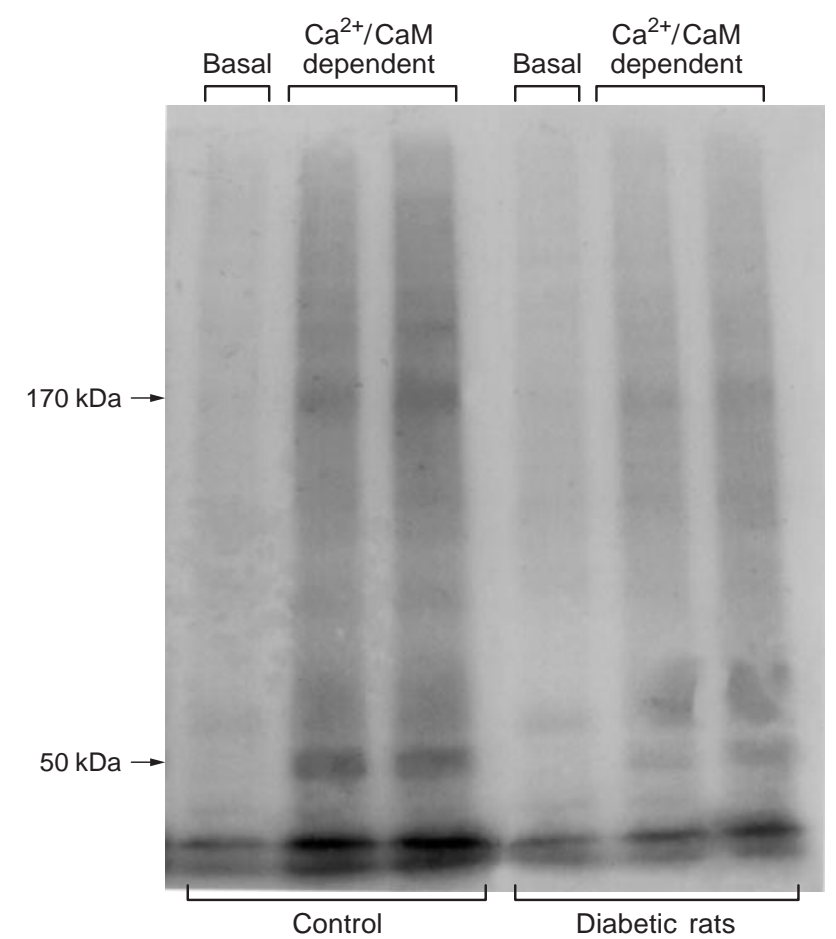

Fig.3. Representative autoradiography of $\mathrm{Mg}^{2+}$-dependent (basal) and $\mathrm{Ca}^{2+} / \mathrm{CaM}$-dependent phosphorylation of hippocampal PSD ( $n=12$ out of 3 independent experiments) in control and diabetic rats. The $170 \mathrm{kDa}$ arrow head indicates the NR2A/B phosphorylation. The $50 \mathrm{kDa}$ arrow head indicates the autophosphorylation of the $\alpha$-subunit of CaMKII

this issue, CaMKII-dependent phosphorylation of exogenously added synthetic peptide (syntide-2) was done (Fig.5). In these experimental conditions $\mathrm{Ca}^{2+} /$ CaM stimulated phosphorylation of syntide- 2 was decreased in cortical and hippocampal PSD from diabetic rats compared with control rats. This decrease in $\mathrm{Ca}^{2+} / \mathrm{CaM}$ stimulated syntide- 2 phosphorylation was quantitatively similar (about $60 \%$ in the cortex and $30 \%$ in the hippocampus) to that observed in the post-hoc phosphorylation assay for the endogenous substrates NR2A/B. Again no difference was observed in basal phosphorylation of the exogenous substrate syntide-2. These data suggest that the observed reduction in CaMKII-dependent phosphorylation is not only due to a lack of one of the endogenous substrates (NR2B), but is also related to a decreased activity, being an intrinsic property of the PSD-associated CaMKII in diabetic rats.

Effect of the insulin intervention treatment. It has been shown previously that a deficit in behavioural learning and hippocampal plasticity in STZ-diabetic rats can be fully prevented but only partially reversed by insulin treatment [31].

The insulin treatment regimen effectively restored blood glucose and body weight towards control values (Table 1).

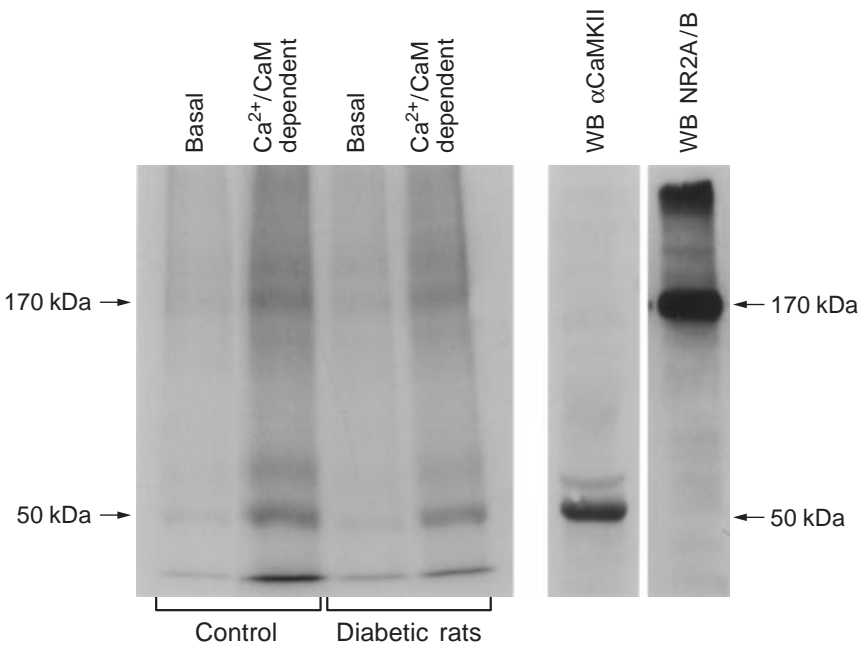

Fig. 4. Representative autoradiography of immunoprecipitation with anti NR2A/B of $\mathrm{Mg}^{2+}$-dependent (basal) and $\mathrm{Ca}^{2+}$ / CaM dependent phosphorylated hippocampal PSD $(n=12$ of 3 independent experiments) in control and diabetic rats. The $170 \mathrm{kDa}$ arrow head indicates the NR2A/B phosphorylation. The $50 \mathrm{kDa}$ arrow head indicates the autophosphorylation of the $\alpha$ subunit of CaMKII. Leftmost lanes: identification by Western blot of NR2A/B and CaMKII $\alpha$ in the immunocomplex

In our study we tested whether, under the same conditions as before, the insulin treatment would affect the CaMKII activity in PSD. Figure 6A shows results of phosphorylation of syntide-2 using hippocampal PSD obtained from age-matched control rats, 7-months-old diabetic, and 7-months-old diabetic rats treated with insulin for the last 3 months. As in animals with a duration of diabetes of 4 months (Fig.5), CaMKII activity is reduced by about $40 \%$ in hippocampal PSD of 7 months diabetic rats compared with control rats. Insulin treatment induced a moderate increase in CaMKII activity but failed to restore it to control level. Note that this effect is paralleled by a modest increase in NR2B protein concentrations in PSD as shown by Western blot analysis (Fig. 6B). No changes in immunostaining of other PSD proteins (Fig.1) were observed (data not shown).

\section{Discussion}

In this study we have evaluated the effects of a chronic diabetic status on gene expression and protein concentrations of NMDA receptor subunits in the brain and examined the phosphorylation of specific NMDA receptor subunits mediated by CaMKII both in a consolidated status diabeticus and after a prolongued insulin intervention treatment. Our main finding is that NMDA receptor subunit NR2B expression is reduced. Furthermore, the CaMKII-dependent ser/thr phosphorylation of both NR2A and NR2B subunits of the NMDA receptor is changed in 
A

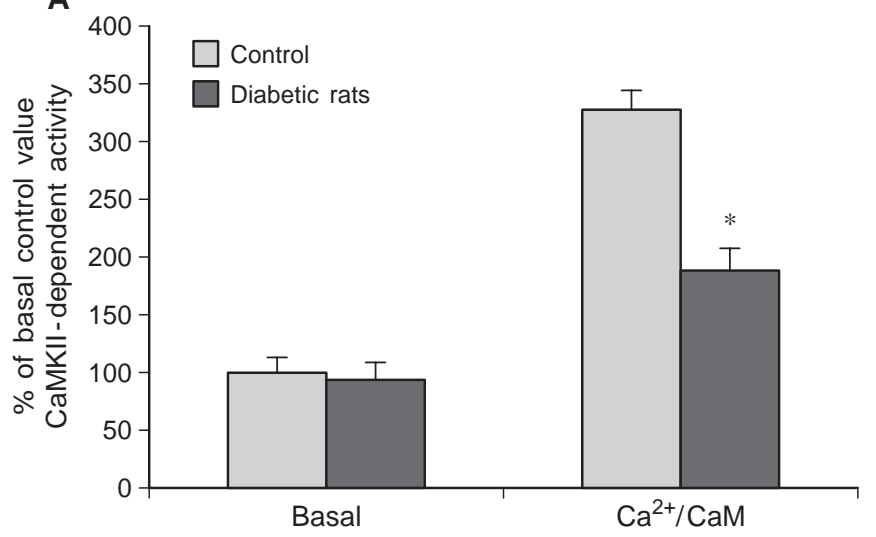

B

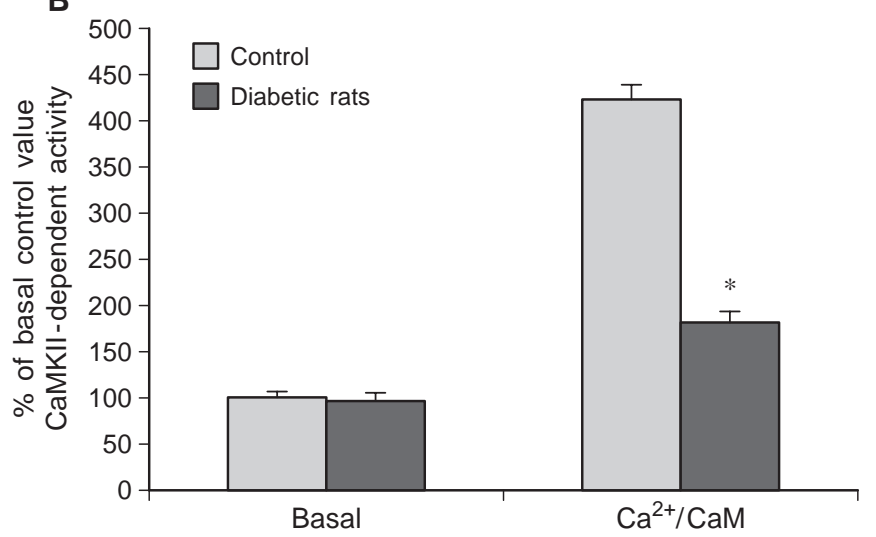

Fig. 5. $\mathrm{Mg}^{2+}$-dependent (basal) and $\mathrm{Ca}^{2+} / \mathrm{CaM}$-dependent activity of CaMKII from cortical (A) and hippocampal (B) PSD in control and diabetic rats using the syntide- 2 as exogenous substrate. Data are expressed as \% of control basal and stimulated values and represent mean $\pm \operatorname{SEM}(n=6$, of 2 independent experiments; $*=p<0.01$ )

PSD of specific brain areas of diabetic rats. In addition, the activity of CaMKII, which is physically associated with NR2 subunits of NMDA receptor in PSD [25] and mediates their phosphorylation, is reduced in diabetic rats. A 3 months insulin intervention treatment only partially restores these variables.

It should be noted that the functional and molecular changes observed in the STZ-diabetic rat model are considered to be the consequences of hyperglycaemia and insulin deficiency, rather than a consequence of direct STZ toxicity on the brain. This is strongly supported by the observation that in this model functional changes can be fully prevented by insulin treatment immediately following STZ-injection [31]. Moreover, since STZ transport and cytotoxicity is dependent on expression of the GLUT2 glucose transporter [32] and neither the blood brain barrier nor cerebral neurons express the GLUT2 transporters [33], direct toxic effects of STZ on the brain can be ruled out.

The question of how chronic diabetic pathology could change the expression of a specific NMDA re-

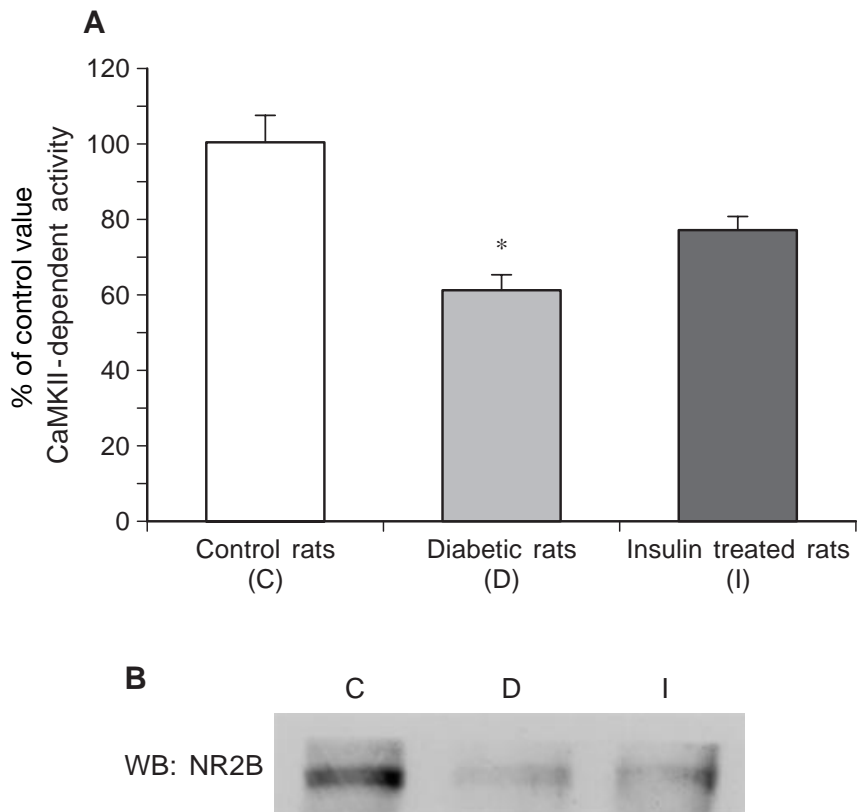

Fig. 6. A CaMKII activity in hippocampal PSD from control (C), diabetic (D) and insulin treated rats (I) using the syntide2 as exogenous substrate. Data are expressed as percentage of basal and stimulated control value and represent mean \pm SEM $(n=6$ of 2 independent experiments; $*=p<0.01)$. B Representative Western blot analysis of a control, diabetic and insulin treated diabetic rat $(C, D, I)$ of NR2B subunit in PSD

ceptor subunit is currently under investigation. Recently, it has been shown that transient ischaemia [34] selectively influences the expression and protein concentration of NR2B, and that mRNA levels of different subunits of NMDA receptors change after 6hydroxydopamine lesions [35], chronic dopamine antagonists treatment [36], oestrogen treatment [37], epileptic seizures [38]. Although the mechanisms governing these changes in message levels remain largely unknown, recently the hypothesis that growth factors might influence these variables has been put forward. In particular nerve growth factor (NGF) might influence the activity of the promoter region of NR1 subunit gene, possibly through increasing the expression of the early-gene family of transcription factors, such as NGF-inducible factors (NGFIs) or early growth reaction factors (Egr) [39]. The possibility that growth factors other than NGF can influence the expression of NMDA receptor subunits is likely. Diabetes is known to affect a number of growth factors among which are NGF and IGF. It has been reported previously that in diabetic rats insulin growth factor-1 (IGF-1) and IGF-2 mRNA content is reduced in sciatic nerve and that circulating concentration of IGF-1 tend to be reduced in diabetic patients and in STZ-treated diabetic rats $[40,41]$. In this respect, the possibility that IGF-1/IGF-2 might influence the activity of the promoter of different NR2 subunits is particularly intriguing. The observation 
that after a prolonged treatment of diabetic rats with insulin, the concentration of NR2B protein is partially restored might support such a hypothesis. This effect appears specific for NR2B subunits, since the expression of other NR subunits or other GluR receptors, such as GluR2/3 (data not shown) is not modified in diabetic rat brain.

Concomitantly and irrespectively of the reduced NR2B concentration in PSD, the activity of CaMKII-associated with PSD is decreased in diabetic rats when compared with control rats, as shown by CaMKII assay done on exogenous substrate. This raises the possibility that other CaMKII substrates present in PSD could also show a reduced degree of phosphorylation (i.e. AMPA receptors) [20]. Why CaMKII activity is down-regulated in diabetic rats and whether this is due to disturbances in presynaptic function, such as neurotransmitter release, or solely to postsynaptic plasticity, is presently under investigation. An involvement of disturbance of presynaptic function is, however, unlikely, since PPF is unmodified in diabetic rats when compared with control rats.

These findings describing a malfunctioning of post-synaptic components define another tile of the complex pathogenesis of cerebral disorders associated with diabetic pathology. Diabetes is known to induce alterations of second messenger systems such as cAMP [42] and phosphoinositide [43], as well as alterations of protein kinases other than CaMKII, such as PKC [44]. Moreover, diabetic pathology is known to produce a dysfunction in calcium homeostasis [45]. Indeed, our data suggest that a dysfunction in intracellular calcium regulation could occur at the postsynaptic side and it is reflected in a defective activation of CaMKII. Reduced CaMKII activity, in turn, could disturb the delicate balance between phosphatase and kinase activity at the postsynaptic side, thus hampering expression of LTP and favouring expression of LTD, as has been reported in STZ-diabetic rats [9].

Are the changes in NR2B expression and CaMKII activity sufficient to explain changes in synaptic plasticity described previously in diabetic rats? It is known that an imbalance between the NR2B and NR2A subunit composition change the physiology of cells bearing NMDA receptor. Experiments done using recombinantly expressed NMDA receptors indicate that the subunit composition strongly affects the electrophysiological properties of NMDA receptor subtypes. In particular the NR2A-containing receptor channels differ from the other channel subtypes by considerable shorter offset decay time courses following brief application of L-glutamate [46]. The offset decay time course is thought to be crucial for the coincidence detection of pre- and post-synaptic activities; whether these kinetic characteristics can also represent a molecular rationale for a different vulnerability is still controversial. It may also be possible that chronic metabolic stress induces changes in the stoichiometric composition of the NMDA receptor complex, thus influencing the kinetic of excitatory transmission in these animals.

NMDA receptor channel opening and duration can be regulated by phosphorylation of specific subunits mediated by different kinases [47]. In particular NR1 subunits are phosphorylated by PKC [48, 49] whereas NR2B subunits may be phosphorylated both by CaMKII [21, 25] and by a tyrosine kinase $[47,50]$. In both cases phosphorylation is of functional relevance. Here we show that CaMKII-dependent phosphorylation of NR2A and B subunits is markedly reduced in both cortex and hippocampus of diabetic rats. Therefore, both the decreased expression of NR2B subunit and the decreased CaMKII-dependent phosphorylation of NR2 subunits could be involved in the changed expression of LTP/LTD observed in diabetic rats. Electrophysiological studies, using intracellular recording techniques, are currently in use to examine the functional consequences of changes in the expression and phosphorylation of subunits.

In addition, insulin intervention treatment of diabetic rats for 3 months after the establishment of diabetes only partially restores CaMKII activity as well as NR2B levels. Recently it has been reported that insulin intervention treatment which is able to nearly normalize blood glucose concentrations, body weights and impaired nerve conduction velocities had only a limited effect on water maze performances in STZ treated rats and on LTP [7]. Our data at the molecular level showing only a moderate effect on CaMKII activity and NR2B levels are in line with this observation, emphasising the functional significance of the present finding.

In conclusion, CaMKII activity as well as NR2B levels, are affected in diabetic rats. Insulin treatment can restore both these parameters only partially. These changes may represent the molecular correlate of previously reported deficits in learning and hippocampal plasticity.

\section{References}

1. Mooradian AD (1988) Diabetes and the central nervous system. Endocr Rev 9: 346-356

2. Di Mario U, Morano S, Valle E, Pozzessere G (1995) Electrophysiological alterations of the central nervous system in diabetes mellitus. Diabetes Metab 11(3): 259-277

3. McCall AL (1992) The impact of diabetes on the CNS. Diabetes 41: 557-570

4. Biessels GJ, Kapelle AC, Bravenboer B, Erkelens DW, Gispen WH (1994) Cerebral function in diabetes mellitus. Diabetologia 37: 643-650

5. Biessels GJ, Kamal A, Ramakers GM et al. (1996) Place learning and hippocampal synaptic plasticity in streptozotocin-induced diabetic rats. Diabetes 45: 1259-1266 
6. Chabot C, Massicotte G, Milot M, Trudeau F, Gagne J (1997) Impaired modulation of AMPA receptors by calcium-dependent processes in streptozotocin-induced diabetic rats. Brain Res 768(1-2): 249-256

7. Kamal A, Biessels GJ, Urban IJA, Gispen WH (1998) Hippocampal synaptic plasticity in streptozotocin-diabetic rats: impairment of long-term potentiation and facilitation of long-term depression. Neuroscience 83(3): 707-715

8. Artola A, Singer W (1993) Long-term depression of excitatory synaptic transmission and its relationship to long-term potentiation. Trends Neurosci 16: 480-487

9. Bliss TV, Collingridge GL (1993) A synaptic model of memory: long-term potentiation in the hippocampus. Nature 361: 31-39

10. Schwartz JH (1993) Cognitive kinases. Proc Natl Acad Sci USA 90: 8310-8313

11. Mulkey RM, Endo S, Shenolikar S, Malenka RC (1994) Involvement of a calcineurin/inhibitor-1 phosphatase cascade in hippocampal long-term depression. Nature 369: 486-488

12. O'Dell TJ, Kandel ER (1994) Low-frequency stimulation erases LTP through an NMDA receptor-mediated activation of protein phosphatases. Learning and Memory 1: 129-139

13. Nakanishi S (1992) Molecular diversity of glutamate receptors and implications for brain function. Science 258: 597-603

14. Hollmann M, Heinemann S (1994) Cloned glutamate receptors. Annu Rev Neurosci 17: 31-108

15. Monyer H, Sprengel R, Herb A et al. (1992) Heteromeric NMDA receptors: molecular and functional distinction of subtypes. Science 256: 1217-1221

16. Kennedy MB (1993) The postsynaptic density. Current Opinion in Neurobiology 3: 732-737

17. Ehlers MD, Zhang S, Bernhardt JP, Huganir RL (1996) Inactivation of NMDA receptors by direct interaction of calmodulin with the NR1 subunit. Cell 84: 745-755

18. Rogers SW, Hughes TE, Hollmann M, Gasic GP, Deneris ES, Heinemann S (1991) The characterization and localization of the glutamate receptor subunit GluR1 in the rat brain. J Neurosci 11: 2713-2724

19. Kennedy MB (1997) The postsynaptic densities at glutamatergic synapses. Trends Neurosci 20: 264-268

20. Barria A, Muller D, Derkach V, Griffith LC, Soderling TR (1997) Regulatory phosphorylation of AMPA-type glutamate receptors by CaM-KII during long-term potentiation. Science 276(5321): 2042-2045

21. Omkumar RV, Kiely MJ, Rosenstein AJ, Min KT, Kennedy MB (1996) Identification of a phosphorylation site for calcium/calmodulin dependent protein kinase II in the NR2B subunit of the N-methyl-D-aspartate receptor. J Biol Chem 271: 31670-31678

22. Zucker RS (1989) Short-term synaptic plasticity. Annu Rev Neurosci 12: 13-31

23. Carlin RK, Grab DJ, Cohen RS, Siekevitz P (1980) Isolation and characterization of Post Synaptic Densities from various brain regions: enrichment of different types of Post Synaptic Densities. J Cell Biol 86: 831-843

24. Suzuki T, Okumura-Noji K, Tanaka R, Tada T (1994) Rapid translocation of cytosolic $\mathrm{Ca}^{2+} /$ Calmodulin-dependent protein kinase II into postsynaptic densitiy after decapitation. J Neurochem 63: 1529-1537

25. Gardoni F, Caputi A, Cimino M, Pastorino L, Cattabeni F, Di Luca M (1998) CaMKII is associated to NR2A/B subunits of NMDA receptor in Post Synaptic Densities. J Neurochem 71: 1733-1741
26. Fukunaga K, Stoppini L, Miyamoto E, Muller D (1993) Long-term potentiation is associated with an increased activity of $\mathrm{Ca}^{2+} /$ calmodulin-dependent protein kinase II. J Biol Chem 268: 7863-7867

27. Lewis ME, Sherman TG, Watson SJ (1985) In situ hybridisation histochemistry with synthetic oligonucleotides: strategies and methods. Peptides 6: 75-87

28. Di Luca M, Cimino M, De Graan PNE, Oestreicher AB, Gispen WH, Cattabeni F (1991) Microencephaly reduces the phosphorylation of PKC substrate B-50/GAP43 in rat cortex and hippocampus. Brain Res 538: 95-101

29. Di Luca M, Caputi A, Cinquanta M et al. (1995) Changes in Protein Kinase $\mathrm{C}$ and its presynaptic substrate after intrauterine exposure to methylazoxymethanol, a treatment inducing cortical and hippocampal damage and cognitive impairments. Eur J Neurosci 7: 899-906

30. Paxinos G, Watson C, Pennisi M, Topple A (1985) Bregma, lambda and the interaural midpoint in stereotaxic surgery with rats of different sex, strain and weight. J Neurosci Methods 13(2): 139-143

31. Biessels GJ, Kamal A, Urban IJ, Spruijt BM, Erkelens DW, Gispen WH (1998) Water maze learning and hippocampal synaptic plasticity in streptozotocin-diabetic rats: effect of insulin treatment. Brain Res 800: 125-135

32. Schnedl WJ, Ferber S, Johnson JH, Newgard CB (1994) STZ transport and cytotoxicity. Specific enhancement in GLUT2-expressing cells. Diabetes 43: 1326-1333

33. Rayner DV, Thomas ME, Trayhurn P (1994) Glucose transporters (GLUTs 1-4) and their mRNAs in regions of the rat brain: insulin-sensitive transporter expression in the cerebellum. Can J Physiol Pharmacol 72: 476-479

34. Zhang L, Hsu JC, Takagi N, Gurd JW, Wallace MC, Eubanks JH (1997) Transient global ischemia alters NMDA receptor expression in rat hippocampus-correlation with decreased immunoreactive protein levels of the NR2A/2B subunits, and altered NMDA receptor functionality. J Neurochem 69(5): 1983-1994

35. Tremblay M, Salin P, Soghomonian JJ (1995) Effect of 6OHDA lesions on striatal mRNA levels encoding for glutamate receptors subunits. Neuroreport 6: 2225-2229

36. Fitzgerald LW, Deutch AY, Gasic G, Heinemann SF, Nestler EJ (1995) Regulation of cortical and subcortical glutamate receptor subunits expression by antipsychotic drugs. J Neurosci 15: 2453-2461

37. Brann DW, Zamorano PL, Chorich LP and Mahesh VB (1993) Steroid hormone effects on NMDA receptor binding and NMDA receptor mRNA levels in the hypothalamus and cerebral cortex of the adult rat. Neuroendocrinology 58: 666-672

38. Pratt GD, Kokaia M, Bengzon J et al. (1993) Differential regulation of N-methyl-D-aspartate receptor subunit messenger RNAs in kindling-induced epileptogenesis. Neurosci 57: 307-318

39. Bai G, Kusiak JW (1997) Nerve Growth Factor up-regulates the N-Methyl-D-Aspartate Receptor subunit 1 Promoter in PC12 cells. J Biol Chem 272: 5936-5944

40. Ekstrom PA, Kanje M, Skottner A (1989) Nerve regeneration and serum levels of insulin-like growth factor-I in rats with streptozotocin-induced insulin deficiency. Brain Res 496: 141-147

41. Brewster WJ, Fernyhough P, Diemel LT, Mohiuddin L, Tomlinson DR (1994) Diabetic neuropathy, nerve growth factor and other neurotrophic factors. Trends Neurosci 17: 321-325

42. Lowery JM, Berti-Mattera LN, Zhu X, Peterson RG, Eichberg, J (1989) Relationship of ATP turnover, polyphosphoinositide metabolism, and protein phosphorylation in 
sciatic nerve and derived peripheral myelin subfractions from normal and streptozotocin diabetic rats. J Neurochem 52: 921-932

43. Mathew J, Bianchi R, McLean WG et al. (1997) Phosphoinositide metabolism Na,K-ATPase and protein kinase $\mathrm{C}$ are altered in peripheral nerve from Zucker diabetic fatty rats $(\mathrm{ZDF} / \mathrm{Gmi}-\mathrm{f} \alpha)$. Neurosci Res Commun 20: 21-30

44. Makar TK, Hungund BL, Cook GA, Kashfi K, Cooper AJL (1995) Lipid metabolism and membrane composition are altered in the brains of type II diabetic mice. J Neurochem 64: 2159-2168

45. Biessels GJ, Gispen WH (1996) The calcium hypothesis of brain aging and neurodegenerative disorders: significance in diabetic neuropathy. Life Sci 59: 379-387

46. Monyer H, Burnashev N, Laurie DJ, Sakmann B, Seeburg PH (1994) Developmental and regional expression in the rat brain and functional properties of four NMDA receptors. Neuron 12: 529-540

47. Wang YT, Yu XM, Salter MW (1996) $\mathrm{Ca}^{2+}$ independent reduction of N-methyl-D-aspartate channel activity by protein tyrosine phosphatase. Proc Natl Acad Sci USA 93: 1721-1725

48. Tingley WG, Roche KW, Thompson AK, Huganir RL (1993) Regulation of NMDA receptor phosphorylation by alternative splicing of the C-terminal domain. Nature 364: 70-73

49. Ehlers MD, Tingley WG, Huganir, RL (1995) Regulated subcellular distribution of the NR1 subunit of the NMDA receptor. Science 269: 1734-1737

50. Moon IS, Apperson ML, Kennedy MB (1994) The major tyrosine phosphorylated protein in the Post Synaptic Density fraction is N-Methyl-D-Aspartate receptor subunit 2B. Proc Natl Acad Sci USA 91: 3954-3958 